\title{
EVALUASI RENCANA AKSI MITIGASI DENGAN PENDEKATAN EKONOMI HIJAU DI KABUPATEN JAYAPURA
}

\author{
Martha Christina Yufuai ${ }^{1 *}$, Dodik Ridho Nurrochmat ${ }^{2}$, Suyanto ${ }^{3}$ \\ ${ }^{1}$ Program Studi Ilmu Pengelolaan Sumberdaya Alam dan Lingkungan, Sekolah Pascasarjana, Institut \\ Pertanian Bogor (IPB) \\ 2Departemen Manajemen Hutan, Fakultas Kehutanan, Institut Pertanian Bogor (IPB) \\ ${ }^{3}$ World Agroforestry Centre \\ *Email: athajoef@gmail.com
}

\section{RINGKASAN}

Pertumbuhan ekonomi di Kabupaten Jayapura bertumpu pada sektor berbasis lahan seperti pertanian, perkebunan dan kehutanan. Kondisi ini harus dikelola dalam kerangka ekonomi hijau (green economy)sehingga dapat menjadi jalan tengah antara peningkatan populasi dan penurunan sumber daya lahan. Kabupaten Jayapura memiliki luas kawasan hutan sebesar 1.225.505 ha atau 70,73\% dari luas Kabupaten Jayapura. Kawasan hutan terdiri dari Hutan Lindung 661.799 ha (38,04\%), Cagar Alam 8.262 ha (0,74\%), Hutan Suaka Marga Satwa 160.163 ha $(9,23 \%)$ dan Hutan Budidaya 395.281 ha (22,72\%). Penelitian ini bertujuan untuk menganalisis dampak aksi mitigasi terhadap pertumbuhan ekonomi Kabupaten Jayapura dan membangun strategi kebijakan bagi Kabupaten Jayapura dalam Green Growth Economy. Penelitian ini menggunakan perangkat LUMENS dalam menganalisi input-output ekonomi Kabupaten Jayapura untuk mengetahui dampak aksi mitigasi dan trade off analysis dalam pertumbuhan ekonomi, dan membangun strategi pertumbuhan ekonomi hijau di Kabupaten Jayapura. Kabupaten Jayapura dapat memanfaatkan sumberdaya hutan untuk pemerataan ekonomi, sepanjang pemerintah menjadikan sumberdaya alam sebagai penghasil devisa dan dapat mencipatakan kesejahteraan masyarakat, maka kawasan yang dapat dijadikan sumberdaya stock carbon adalah kawasan konservasi (9,70\%) dan kawasan hutan lindung (38,04\%). Makna dari pembangunan ekonomi hijau di Kabupaten Jayapura adalah keterlibatan masyarakat dalam proses pembangunan, menjadi investasi dalam modal sosial, sehingga pemanfaatan sumberdaya alam dalam bentuk formal maupun informal. Memberikan ruang bagi pemerintah untuk menciptakan investasi sesuai dengan fungsi kawasannya. Strategi pembangunan ekonomi hijau Kabupaten Jayapura dapat dicapai dengan dukungan kebijakan (policy making), kerjasama serta koordinasi (patnership) dan pemerataan pembangunan.

Katakunci: Aksi Mitigasi, Ekonomi Hijau, Kabupaten Jayapura 


\section{PERNYATAAN KUNCI}

1. Aktifitas ekonomi di Kabupaten Jayapura sebagian besar masih berbasis lahan seperti pertanian, perkebunan dan kehutanan. Aktifitas tersebut mendorong adanya perubahan tutupan lahan dan memberikan pengaruh pada penyerapan emisi gas rumah kaca yang kemudian dapat memicu perubahan iklim.

2. Kebijakan ekonomi harus menengahi kebutuhan pemanfaatan sumberdaya alam dan mitigasi perubahan iklim. Untuk itu, pemerintah Indonesia berkomitmen untuk menurunkan emisi gas rumah kaca melalui Peraturan Presiden nomor 61 Tahun 2011 tentang Rencana Aksi Nasional Penurunan Emisi Gas Rumah Kaca (RAN-GRK) dan Undang-undang (UU) Nomor 16 Tahun 2016 Tentang Pengesahan Paris Agreement to The Nations Framework Convention on Climate Change.

3. Upaya Pemerintah Kabupaten Jayapura dalan Rencana Aksi Mitigasi telah menyusun 8 rencana aksi yang terdiri dari: 1) pencegahan penurunan cadangan karbon; 2) Implementasi NKT (Nilai Konservasi Tinggi) hutan tanaman; 3) pengembangan sumberdaya hutan (hutan lindung); 4) peningkatan cadangan/serapan karbon; 5) Rehabilitasi lahan kritis menjadi hutan sekunder kerapatan rendah; 6) Rehabilitasi pada lahan kritis menjadi hutan produksi; 7) Penanaman pohon di lahan kritis (rawan longsor); dan 8) Penerapan sistem agroforestri.

4. Upaya memacu pertumbuhan Produk Domestik Bruto (PDRB) harus memperhatikan nilai penyusutan sumberdaya alam dan rusaknya lingkungan (degradasi), untuk tetap menjaga kestabilan karbon dalam memanfatkan kawasan sesuai fungsinya.

\section{REKOMENDASI KEBIJAKAN}

1. Perlu percepatan pembangunan ekonomi hijau di Kabupaten Jayapura sebagai pembangunan berkelajutan yang merata di setiap wilayah. Kebijakan pembangunan ekonomi harus memperhatikan besaran dampak pada peningkatan pembangunan, ekonomi, ekologi (lingkungan) dan sosial budaya masyarakat.

2. Perlu melakukan prioritas pembangunan dari delapan aksi mitigasi oleh Pemerintah Kabupaten Jayapura. Hasil analisis yang dilakukan menemukan bahwa aksi_8 (penerapan sistem agroforestri pada lahan kritis dan lahan pertanian semusim) dapat menjadi prioritas dalam peningkatan ekonomi masyarakat.

3. Pertumbuhan ekonomi hijau dapat menjadi model pembangunan dalam 
pembangunan berkelanjutan untuk mencapai kesejahteraan masyarakat dengan mejaga kestabilan emisi GRK di Kabupaten Jayapura.

\section{PENDAHULUAN}

Perubahan iklim saat ini menjadi tantangan utama bagi pembangunan di Indonesia. Perubahan iklim memberikan dampak bagi pembangunan ekonomi. Sektor perekonomian di Indonesia sebagian besar masih ditopang oleh kegiatan usaha yang berbasis lahan seperti pertanian, perkebunan dan kehutanan. Keberhasilan dan produktivitas sektor-sektor ini sangat bergantung pada kondisi iklim. Penyebab utama terjadinya perubahan iklim karena aktivitas manusia yang melakukan eksploitasi sumberdaya alam yang berlebihan tanpa memperhatikan dampaknya terhadap lingkungan. Aktivitas manusia dan besarnya kebutuhan lahan memicu perubahan iklim, yang mengakibatkan peningkatan konsentrasi GRK. Hal ini menyebabkan berkurangnya luasan tutupan lahan sebagai sumber cadangan karbon (carbon stock). GGGI (2015) menyatakan eksploitasi sumberdaya alam yang berlebihan tanpa memperhatikan dampak lingkungan, akan mempengaruhi ketersediaan sumber daya alam dari sisi kualitas dan kuantitas. Akibatnya biaya sosial dari polusi dan perubahan iklim semakin meningkat dan ekositem yang mendukung kehidupan akan terancam.
Keadaan tersebut pada akhirnya akan menyebabkan keberlanjutan kesejahteraan manusia secara fundamental juga ikut terancam.

Pemerintah Indonesia dalam menghadapi tantangan perubahan iklim telah berkomitmen untuk menurunkan emisi sebesar 29\% dengan upaya sendiri dan sampai 41\% dengan bantuan internasional sebagaimana tertuang dalam UU No 16 tahun 2016. Undang-undang ini merupakan hasil ratifikasi Paris Agreement to The Nations Framework Convention on Climate Change. Komitmen ini menguatkan peraturan yang telah ada sebelumnya yaitu Peraturan Presiden nomor 61 Tahun 2011 tentang Rencana Aksi Nasional Penurunan Emisi Gas Rumah Kaca (RAN-GRK) yang menjadi dasar acuan pelaksanaan penurunan emisi GRK di seluruh Indonesia. RAN-GRK tersebut dijabarkan pada tingkat daerah (provinsi) dalam bentuk Rencana Aksi Daerah Gas Rumah Kaca (RAD-GRK) sebagai dasar bagi pemerintah daerah untuk melakukan berbagai upaya menurunkan emisi GRK di wilayahnya. Kebijakan pembangunan rendah karbon (low carbon) adalah pembangunan ekonomi yang berlangsung mampu mepertahankan dan menjaga kestabilan emisi GRK untuk mencapai pembangunan berkelanjutan secara ekonomi, lingkungan dan sosial.

Peran strategis Kabupaten Jayapura berkontribusi dalam penurunan emisi GRK 
dengan menyusun rencana aksi mitigasi untuk mendukung komitmen pemerintah Provinsi Papua dalam Peraturan Gubernur Nomor 9 Tahun 2012 tentang rencana aksi daerah penurunan emisi GRK tahun 2013 sampai 2020. Hal tersebut dapat membantu pembangunan ekonomi di Kabupaten Jayapura hanya cenderung ekstraktif dengan kondisi pertumbuhan ekonomi sangat bergantung pada sektor sumberdaya alam.

Pembangunan ekonomi hijau adalah model perencanaan dan perancangan pembangunan nasional, dengan pendekatan pembangunan ekonomi yang rendah karbon, yang konsep pengelolaan sumberdaya alam disesuaikan dengan kemampuan fisik, sosial dan ekonomi daerah untuk kesejahteraan masyarakat (Pearce et al. 1992). Bagaimana pembangunan ekonomi di Kabupaten Jayapura dapat melaksanakan pertumbuhan ekonomi hijau?" merupakan pertanyaan penting yang akan dijawab dalam penelitian ini.

\section{SITUASI TERKINI}

\section{Aksi Mitigasi Karbon ( $\left.\mathrm{CO}_{2}\right)$}

1. Proyeksi Emisi dari Aksi Mitigasi

Dampak aksi mitigasi terhadap pertumbuhan ekonomi dianalisis dengan menggunakan dua indikator makro yaitu PDRB dan pendapatan skenario BAU (Bussines as Usual). Perhitungan perbandingan PDRB, pendapatan skenario
BAU dan skenario aksi mitigasi akan diketahui apakah skenario aksi mitigasi mempunyai pengaruh positif atau negatif terhadap pertumbuhan ekonomi.

Skenario BAU pada tahun 2030 menghasilkan proyeksi PDRB sebesar 1.918.948,31 (juta Rp), untuk mengetahui dampak ekonomi aksi mitigasi adalah PDRB aksi mitigasi dikurangi dengan PDRB BAU. Dampak tingkat pendapatan dari aksi mitigasi diperoleh dengan mengurangi tingkat pendapatan BAU sebesar 682.882,00 (juta Rp) dan tingkat pendapatan PDRB aksi mitigasi. Pada Tabel 1 dapat dilihat dampak ekonomi aksi mitigasi di Kabupaten Jayapura.

Pengurangan emisi berbasis sektor lahan adalah mekanisme pengurangan emisi akibat perubahan penggunaan lahan, dan mengatasi perubahan iklim yang berdampak bagi penghidupan masyarakat secara global. Prinsip penting yang dalam penentuan aksi mitigasi menurut Bappenas (2011) menyatakan upaya penurunan emisi di tingkat daerah, sejalan dengan prinsip penyusunan RAN-GRK yaitu (1) rencana akis mitigasi merupakan bagian yang tidak terpisahkan dari strategi pembangunan daerah, (2) tidak menghambat upaya pembangunan ekonomi dan pengentasan kemiskinan dengan memprioritaskan kesejahteraan masyarakat, (3) terintegrasi antara satu bidang dengan bidang yang lain (cross sectorial issues), (4) dapat dijadikan 
rencanan pembangunan dengan pendekatan yang baru, dan (5) keterlibatan stakeholder pembangunan di daerah dari berbagai unsur, meningkatkan kepemilikan (ownership) secara partisipasi dalam kurun waktu yang telah ditetapkan.

Proses penyusunan aksi mitigasi dilakukan dengan identifikasi program dan kegiatan pembangunan yang tertuang dalam RPJMD dan Rencana Kerja Perangkat
Daerah (RKPD) dan atau kegiatan yang terintegrasi dengan RPJMN dan RKP pemerintah pusat. Dengan melibatkan berbagai stakeholder, diskusi penentuan aksi mitigasi, pelaksanaan konsultasi publik. Penyusunan Aksi mitigasi dini telah disetujui oleh para pihak di lingkungan pemerintah dan masyarakat Kabupaten Jayapura. Skenario aksi mitigasi disajikan pada Tabel 1.

Tabel 1. Skenario aksi mitigasi di Kabupaten Jayapura periode tahun 2016 sampai 2030

\begin{tabular}{|c|c|c|c|}
\hline No & Aktivitas Mitigasi & $\begin{array}{c}\text { Lokasi kegiatan } \\
\text { (Unit Perencanaan) }\end{array}$ & Perencanaan Pembangunan yang akan datang \\
\hline 1 & $\begin{array}{l}\text { Mempertahankan tutupan hutan } \\
\text { primer dan sekunder }\end{array}$ & Cagar Alam & $\begin{array}{l}\text { Perlindungan ekosistem dan lingkungan yang ada di } \\
\text { dalamnya }\end{array}$ \\
\hline 2 & $\begin{array}{l}\text { Implementasi NKT (Nilai } \\
\text { Konservasi tinggi) }\end{array}$ & Hutan Tanaman & $\begin{array}{l}\text { Ada pengembangan penggunaan lahan dari hutan } \\
\text { sekunder kerapatan tinggi untuk komoditas } \\
\text { perkebunan } 10 \% \text { ke sawit dan } 5 \% \text { coklat }\end{array}$ \\
\hline 3 & Pengamanan Sumber Daya Hutan & Hutan Lindung & $\begin{array}{l}\text { Perubahannya mengikuti perubahan historis, kecuali } \\
\text { pemukiman saja yang tetap dan tidak bertambah }\end{array}$ \\
\hline 4 & $\begin{array}{l}\text { Kegiatan konservasi atau restorasi } \\
\text { melalui penanaman kembali hutan } \\
\text { sagu dari lahan terdegradasi }\end{array}$ & Sempadan Danau & $\begin{array}{l}\text { Agroforestri pada lahan semak belukar (tanaman } \\
\text { sagu) }\end{array}$ \\
\hline 5 & $\begin{array}{l}\text { Rehabilitasi lahan kritis menjadi } \\
\text { hutan sekunder kerapatan rendah } \\
\text { sepanjang Cagar Alam Cycloop }\end{array}$ & Cagar Alam & $\begin{array}{l}\text { Perlindungan ekosistem dan lingkungan yang ada di } \\
\text { dalamnya }\end{array}$ \\
\hline \multirow[t]{3}{*}{6} & $\begin{array}{l}\text { Rehabilitasi pada lahan kritis } \\
\text { menjadi hutan sekunder kerapatan } \\
\text { rendah }\end{array}$ & $\begin{array}{l}\text {-Hutan Produksi } \\
\text { Konversi }\end{array}$ & $\begin{array}{l}\text { - Ada pengembangan penggunaan lahan dari hutan } \\
\text { sekunder kerapatan tinggi untuk komoditas } \\
\text { perkebunan } 10 \% \text { ke sawit dan } 5 \% \text { coklat }\end{array}$ \\
\hline & & - Hutan Produksi & $\begin{array}{l}\text { - Pengelolaan Hak Pengusahaan Hutan menggunakan } \\
\text { hukum adat sebesar 20\% dari hutan primer menjadi } \\
\text { hutan sekunder kerapatan tinggi }\end{array}$ \\
\hline & & $\begin{array}{l}\text { - Hutan Produksi } \\
\text { Terbatas }\end{array}$ & $\begin{array}{l}\text { - Pemberian ruang kegiatan sebesar 5\% dari hutan } \\
\text { sekunder kerapatan tinggi menjadi hutan sekunder } \\
\text { kerapatan rendah }\end{array}$ \\
\hline 7 & $\begin{array}{l}\text { Penanaman pohon di lahan kritis } \\
\text { menjadi hutan sekunder kerapatan } \\
\text { rendah }\end{array}$ & Rawan Longsor & $\begin{array}{l}\text { Sesuai kondisi perubahan dan penggunaan lahan } \\
\text { sebelumnya }\end{array}$ \\
\hline 8 & $\begin{array}{l}\text { Penerapan sistem agroforestri } \\
\text { pada lahan kritis dan lahan } \\
\text { pertanian semusim }\end{array}$ & Perkebunan Masyarakat & $\begin{array}{l}\text { Penggunaan lahan undisturbed forest akan dibangun } \\
\text { menjadi kebun/agroforetri }\end{array}$ \\
\hline
\end{tabular}

Sumber: Data dokumen LED Kabupaten Jayapura 2017 
Tabel 1 menunjukkan delapan aksi mitigasi yang disusun, adalah upaya-upaya yang dilakukan dalam wilayah administratif Kabupaten Jayapura, baik berdampak secara langsung dan tidak langsung. Delapan aksi yang disusun lebih pada tata kelola lahan dalam perencanaan pembangunan dan fungsi hutan. Hutan dipandang sebagai sumber emisi dan sumber mempertahankan karbon, pada praktek pemanfaatannya untuk penurunan karbon dapat dipertahankan tutupan hutan pada kawasan konservasi pada kawasan Cagar Alam, menegakkan peraturan pada pengguna izin pengelolaan hutan (NKT), serta mengamankan sumberdaya hutan pada kawasan hutan lindung. Peningkatan cadangan karbon dilakukan pada kawsan yang telah terjadi perambahan, illegal logging, faktor bencana, kawasan izin usaha hasil hutan kayu.

Perubahan Undang-undang Nomor 23 Tahun 2014 tentang pemerintahan daerah yang mengatur tentang pembagian urusan antara pusat, provinsi dan pemerintah kabupaten/kota. Perubahan ini akan mengakibatkan terjadinya kelimpahan kewenangan pada urusan kehutanan yang juga akan berpengaruh pada peubahan kewenangan di Kabupaten Jayapura dalam pengelolaan kawasan hutan. Perubahan kewenangan ini mengakibatkan, penerapan aksi mitigasi pada pemanfaatan kawasan hutan menjadi kewenangan pemerintah provinsi, yang artinya bahwa untuk penyelenggaraan aksi_1, aksi_2, aksi_3, aksi_5 dan aksi_6. Tiga aksi mitigasi yang menjadi kewenangan Kabupaten Jayapura adalah pada aksi_4, aksi_7 dan aksi_8, karena titik berat desentralisasi ada pada pemerintah level pemerintah kabupaten/ kota sedangkan kewenangan ada di tingkat provinsi

Aksi mitigasi yang direncanakan, jika dilakukan atau terintegrasi pada dokumen rencana pembangunan strategis Kabupaten Jayapura, yang dirancang pada beberapa unit perencanaan, dalam bentuk pencegahan, pengamanan, rehabilitasi, konservasi atau restorasi dan meningkatkan pertumbuhan ekonomi masyarakat melalui sitem agroforestri. Maka besaran nilai penurunan emisi Kabupaten Jayapura dalam kurun waktu yang sudah ditetapkan berdampak pada rencana pembangunan yang rendah emisi. Perkiraan emisi dari delapan aksi mitigasi disajikan pada Tabel 2.

Pada Tabel 2 memperlihatkan total penurunan emisi aksi mitigasi sebesar $18.92 \%$ atau sebesar 27.672.368,69 ton CO2 eq. Perkiraan penurunan emisi terbesar dihasilkan oleh aksi implementasi NKT sebesar 14,444,558.83 Ton $\mathrm{CO}_{2}$ eq (9,48\%) dan pengamanan sumberdaya hutan sebesar 11,657,259.44 Ton $\mathrm{CO}_{2}$ eq (8.41\%) terhadap baseline. Di sisi lain penurunan emisi terkecil sebesar 67.273,53 Ton $\mathrm{CO}_{2}$ eq (0.04\%). Implementasi NKT mengindikasikan 
peranan penting program dan kegiatan dari aksi mitigasi untuk menurunkan emisi di Kabupaten Jayapura. Johana (2014) menyatakan bahwa tinggi rendahnya penurunan emisi kumulatif tidak hanya berhubungan dengan lokasi unit perencanaan, tetapi berhubungan juga dengan aktivitas yang direncanakan. Hal ini mengartikan bahwa aktivitas yang berbeda dalam suatu unit perencanaan yang sama, akan memberikan pengaruh yang berbeda terhadap penurunan emisi yang dihasilkan.

Tabel 2. Perkiraan penurunan emisi 8 aksi mitigasi

\begin{tabular}{rlrc}
\hline No & \multicolumn{1}{c}{ Aksi Mitigasi } & \multicolumn{2}{c}{ Penurunan Emisi } \\
\hline & \multicolumn{1}{c}{ Ton CO2 eq } & Persentase $(\%)$ \\
\hline 1 & Mempertahankan tutupan hutan primer dan sekunder & $672.335,93$ & 0,44 \\
2 & Implementasi NKT & $14.444 .558,83$ & 9,48 \\
3 & Pengamanan sumberdaya hutan & $11.657 .259,44$ & 8,41 \\
4 & $\begin{array}{l}\text { Kegiatan konservasi atau restorasi melalui penanaman kembali hutan sagu } \\
\text { dari lahan terdegradasi }\end{array}$ & $55.751,53$ & 0,04 \\
5 & $\begin{array}{l}\text { Rehabilitasi lahan kritis menjadi hutan sekunder kerapan rendah sepanjang } \\
\quad \text { Cagar Alam Cyclop }\end{array}$ & $40.443,97$ & 0,03 \\
6 & Rehabilitasi pada lahan kritis menjadi hutan sekunder kerapatan rendah & $153.090,98$ & 0,10 \\
7 & $\begin{array}{l}\text { Penanaman pohon di lahan kritis menjadi hutan sekunder kerapatan } \\
\text { rendah }\end{array}$ & $67.273,53$ & 0,04 \\
$\quad$ Penerapan sistem agroforestri pada lahan kritis dan lahan pertanian & $581.654,48$ & 0,38 \\
\hline Total Penurunan Emisi Kumulatif (2016-2030) & $27.672 .368,69$ & 18,92 \\
\hline Sumber: data LUMENS (diolah) & &
\end{tabular}

Hasil perhitungan emisi komulatif dari rencana aksi mitigasi pada tahun 2016 sampai tahun 2030, menunjukkan bahwa aksi mitigasi pencegahan penurunan cadangan karbon/stabilitas simpanan karbon memberikan kontribusi pengurangan emisi sebesar 96,75\%. Pada aksi mitigasi peningkatan cadangan karbon/serapan karbon memberikan kontribusi sebesar 3,25\%. Hasil ini menunjukkan bahwa keberadaan hutan Kabupaten Jayapura yang masih luas, akan sangat efektif untuk menjaga stabilitas simpanan karbon hutan khususnya pada kawasan hutan lindung dan kawasan hutan konservasi.
Model rencana aksi mitigasi yang dibangun di Kabupaten Jayapura adalah pola pengelolaan kawasan bersifat konservasi, pengelolaan sumberdaya alam secara tradisional menjaga ketahanan (nature sustainability) karena alam memenuhi kebutuhan dasar manusia. Masyarakat memandang hutan sebagai "mama" (mother off earth) mempengaruhi kebijakan pemerintah dalam pengelolaan kawasan hutan lebih pada pengelolaan sumberdaya alam berbasis masyarakat (the commons) yang menjaga lingkungan. Keberadaan masyarakat Papua sama dengan pemahaman yang ditulis Moolakkatu (2010) menyatakan kekuatan hubungan manusia dengan alam yang salaing menguntungkan, 
sehingga secara ekologi, manusia memperhatikan implikasi ekologi dari aktifitas yang dilakukan dalam pemanfaatan sumberdaya alam dapat dimanfaatkan secara berkelanjutan. Hariyadi (2005) menyatakan dalam konteks sosio-kultural di Papua, keterlibatan masyarakat sangat penting, untuk mengatur pengelolaan kawasan sebagai upaya pemberdayaan dan peningkatan kesejahteraan. Pengelolaan yang baik akan mempertahankan hutan lindung (Kaswanto dan Nakagoshi, 2014).

\section{Proyeksi Dampak Aksi Mitigasi} terhadap Pertumbuhan Ekonomi

Intervensi pertumbuhan ekonomi dalam perencanaan pembangunan, memberikan arahan yang jelas dalam pelaksanaan program agar dapat dilakukan secara efektif, sinergis dan tidak terjadi overlapping aktifitas. Sektor berbasis lahan menjadi sektor primer, yang memiliki peran penting dalam peningkatan PDRB, potensi sektor unggulan daerah menjadi sumberdaya pertumbuhan ekonomi.

Tabel 3. Skenario penurunan emisi dan dampak terhadap ekonomi delapan aksi mitigasi Kabupaten Jayapura

\begin{tabular}{|c|c|c|c|c|c|c|c|}
\hline \multirow{2}{*}{$\begin{array}{l}\mathrm{N} \\
\mathrm{o}\end{array}$} & \multirow{2}{*}{$\begin{array}{c}\text { Aksi } \\
\text { Mitigasi }\end{array}$} & \multicolumn{2}{|c|}{ Penurunan Emisi } & \multicolumn{2}{|c|}{ PDRB (juta Rp) } & \multicolumn{2}{|c|}{ Pendapatan (juta Rp) } \\
\hline & & ton $\mathrm{CO}_{2} \mathrm{eq}$ & $\%$ & Aksi & Dampak & Aksi & Dampak \\
\hline 1 & Aksi_1 & $672.335,93$ & 0,44 & $1.905 .836,00$ & $-13.112,31$ & $677.774,00$ & $-5.108,00$ \\
\hline 2 & Aksi_2 & $14.444 .558,83$ & 9,48 & $1.916 .010,00$ & $-2.937,92$ & $682.227,81$ & $-654,19$ \\
\hline 3 & Aksi_3 & $11.657 .259,44$ & 8,41 & $1.789 .162,00$ & $-129.786,08$ & $633.073,03$ & $-49.808,97$ \\
\hline 4 & Aksi_4 & $55.751,53$ & 0,04 & $1.918 .894,93$ & $-53,38$ & $682.849,35$ & $-32,65$ \\
\hline 5 & Aksi_5 & $40.443,97$ & 0,03 & $1.918 .919,71$ & $-28,6$ & $682.897,39$ & 15,39 \\
\hline 6 & Aksi_6 & $153.090,98$ & 0,1 & $1.915 .579,48$ & $-3.368,83$ & 681.649,64 & $-1.232,36$ \\
\hline 7 & Aksi_7 & $67.273,53$ & 0,04 & $1.918 .725,41$ & $-222,9$ & 682.801,61 & $-80,39$ \\
\hline 8 & Aksi_8 & $581.654,48$ & 0,38 & $1.895 .129,38$ & $-23.818,93$ & $673.554,60$ & $-9.327,40$ \\
\hline \multicolumn{2}{|c|}{$\begin{array}{c}\text { Emisi Kumulatif } \\
(2016-2030)\end{array}$} & $27.672 .368,69$ & 18,92 & $15.178 .257,52$ & $-173.328,96$ & $5.396 .827,43$ & $-66.228,57$ \\
\hline
\end{tabular}

Sumber: data LUMENS (diolah)

Kegiatan yang dilakukan dalam rencana aksi mitigasi, baik secara langsung maupun tidak langsung memberikan kontribusi pada penurunan emisi sebesar 27.672.368,69 ton $\mathrm{CO}_{2}$ eq $(18,92 \%)$ (Tabel 3). Kontribusi penurunan emisi pada aksi mitigasi stabilitas simpanan karbon yang berkisar antara 672.335,93 ton $\mathrm{CO}^{2}$ eq sampai $14,444,558,83$ ton $\mathrm{CO}^{2}$ eq $(0,44 \%$ -
9,48\%). Kelompok aksi mitigasi ini dapat dijadikan prioritas bagi Pemerintah Kabupaten Jayapura dalam upaya penurunan emisi GRK. Pada kelompok peningkatan cadangan karbon berkontribusi sebesar 40.443,97 ton $\mathrm{CO}^{2}$ eq sampai $581.654,48$ ton $\mathrm{CO}^{2}$ eq $(0,03 \%$ $0,38 \%$ ). Trade off yang terjadi antara emisi BAU dan emisi aksi pada Gambar 1. 


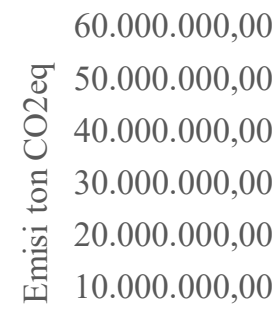

2000-2005 2005-2010 2011-2015 2015-2020 2021-2025 2026-2031

Periode Tahun

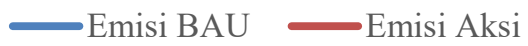

Gambar 1. Perkiraan dampak aksi mitigasi terhadap penurunan emisi

Skenario pembangunan rendah 2030, adalah pelambatan PDRB sebesar karbon dari delapan aksi mitigasi yang dilakukan oleh pemerintah Kabupaten 173.328,96 (juta Rp) dan pendapatan Jayapura memberikan dampak pada sebesar 66.228, 57 (juta Rp) menjadi Trade berkurangnya nilai PDRB dan pendapatan off yang terjadi antara pertumbuhan PDRB .Dampak aksi mitigasi terhadap BAU dan perumbuhan PDRB aksi mitigasi pertumbuhan PDRB Kabupaten tahun pada Gambar 2.

\section{Pertumbuhan PDRB Kabupaten tahun}
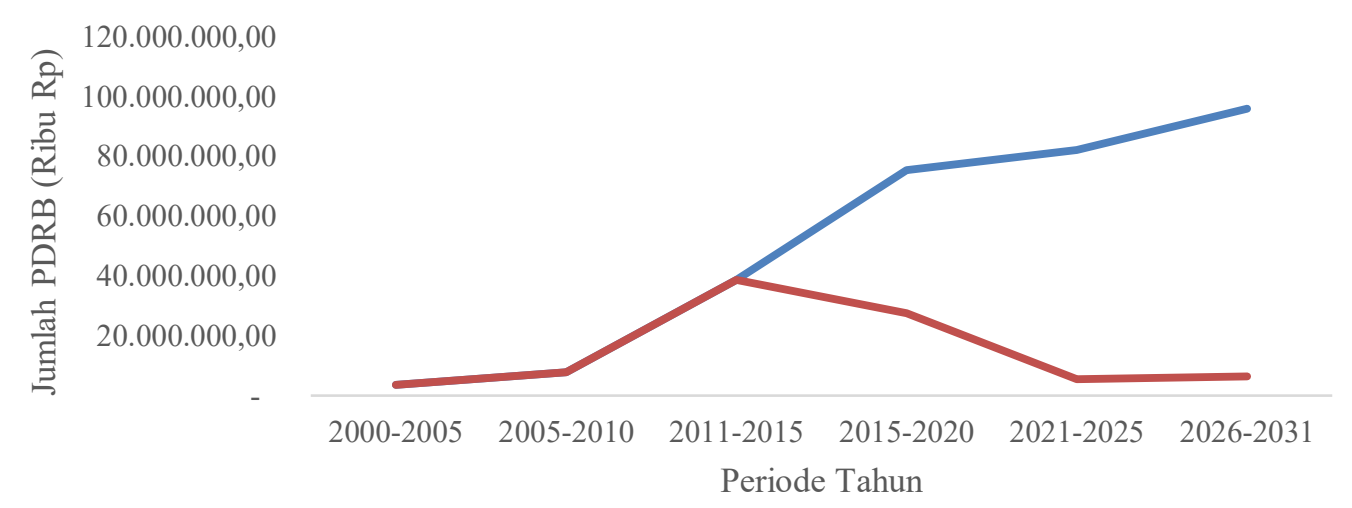

$\longrightarrow$ PDRB BAU $\longrightarrow$ PDRB AKSI

Gambar 2 Perkiraan dampak aksi mitigasi terhadap PDRB

Hasil kajian pengaruh terhadap penurunan emisi tinggi, namun pengaruh terhadap PDRB Kabupaten Jayapura berdampak negatif, artinya jika Pemerintah Kabupaten Jayapura mengintegrasikan aksi mitigasi dalam perencanaan pembangunan Kabupaten Jayapura, maka akan terjadi perlambatan pertumbuhan ekonomi. Keberadaan kawasan hutan yang luas di Kabupaten Jayapura yang dapat dijadikan 
sumber stok karbon, dapat juga digunakan sebagai sumber ekonomi bagi kesejahteraan masyarakat dalam pemerataan pembangunan untuk kesejahteraan masyarakat.

Masalah trade-off antara upaya pengurangan emisi dan pembangunan ekonomi menjadi tantangan bagaimana Kabupaten Jayapura dapat berkontribusi dalam penurunan emisi karbon akan tetapi tetap dapat memberikan kesejahteraan bagi masyarakatnya. Pertumbuhan ekonomi di Kabupaten Jayapura dipengaruhi oleh tingkat pemanfaatan sumberdaya alam, investasi sumberdaya alam memiliki nilai tawar pasar yang tinggi, jika dikelola dengan baik akan memberikan kesejahteraan dan keadilan sosial bagi masyarakat tanpa merusak lingkungan.

\section{METODOLOGI}

\section{Waktu dan Tempat}

Penelitian ini dilakukan di Kabupaten Jayapura dan dilaksanakan pada bulan April sampai November 2018.

\section{Metode Pengumpulan dan Analisis Data}

Penelitian ini menggunakan metode analisis deskriptif kuantitatif untuk menjawab tujuan yang telah ditetapkan. Dalam metode ini, data sekunder dan informasi yang diperoleh diolah dengan menggunakan alat bantu analisis dan disajikan dalam bentuk tabulasi dan grafik (Tabel 4).

Tabel 4 Jenis data, metode analisis dan output yang dihasilkan

\begin{tabular}{|c|c|c|c|c|}
\hline No. & Komponen Tujuan & Data & $\begin{array}{c}\text { Metode } \\
\text { Analisis Data }\end{array}$ & Output \\
\hline 1 & $\begin{array}{l}\text { Mengetahui dampak aksi } \\
\text { mitigasi (trade off analisis) dalam } \\
\text { pertumbuhan ekonomi di } \\
\text { Kabupaten Jayapura }\end{array}$ & $\begin{array}{l}\text { Citra landsat, Peta } \\
\text { RTRW, Peta } \\
\text { Administrasi, Peraturan } \\
\text { Perundangan, satuan } \\
\text { emisi gas rumah kaca }\end{array}$ & $\begin{array}{l}\text { Analisis Deskriptif Tabel } \\
\text { I-O } \\
\text { (menggunakan } \\
\text { LUMENS) }\end{array}$ & $\begin{array}{l}\text { Dampak aksi mitigasi } \\
\text { terhadap } \\
\text { pertumbuhan } \\
\text { ekonomi }\end{array}$ \\
\hline 2. & $\begin{array}{l}\text { Membangun strategi } \\
\text { pertumbuhan ekonomi hijau di } \\
\text { Kabupaten Jayapura }\end{array}$ & $\begin{array}{l}\text { BAU dan dampak aksi } \\
\text { mitigasi tahun } 2016 \\
\text { sampai } 2030\end{array}$ & $\begin{array}{l}\text { Analisis Deskriptif } \\
\text { Kuantitatif } \\
\text { (menggunakan Diagram } \\
\text { Kuznet) }\end{array}$ & $\begin{array}{l}\text { Hubungan kerusakan } \\
\text { lingkungan dengan } \\
\text { peningkatan ekonomi } \\
\text { berbasis lahan }\end{array}$ \\
\hline
\end{tabular}

Beberapa alat bantu analisis yang digunakan adalah:

\section{Land Use Planning for Multiple Environmental Services (LUMENS).} LUMENS merupakan perangkat lunak yang digunakan untuk mengembangkan fungsi unit perencanaan dalam lanskap atau wilayah yang sesuai dengan tujuan perencanaan penggunaan lahan (ICRAF 2017). Pada penelitian ini LUMENS digunakan untuk menganalisis struktur input dan output yang dapat menunjukkan sektor-sektor ekonomi yang mampu memberikan 
kontribusi terhadap pertumbuhan ekonomi wilayah.

2. Diagram Kuznet

Diagram Kuznet digunakan untuk menjelaskan hubungan antara kesenjangan pendapatan dengan degradasi lingkungan.

\section{ANALISIS DAN ALTERNATIF SOLUSI / PENANGANAN}

\section{Pembangunan Ekonomi Hijau Kabupaten Jayapura}

Skenario dampak aksi mitigasi menjadi dasar pertumbuhan ekonomi, jika dihubungkan dengan hipotesis Kuznets akan dapat menjadi sebuah model pembangunan ekonomi hijau di Kabupaten Jayapura. Kurva Kuznet merupakan kurva berbentuk $U$ terbalik yang bersifat multidimensi untuk menggambarkan hubungan jangka panjang antara pendapatan per kapita dengan degradasi lingkungan. Nurrochmat (2017) menyatakan Kuznet's Enviromental Curve adalah studi ekonomi sumberdaya alam yang selaras dengan pembangunan. Penggunaan kurva Kuznets dari inverted $U$ bypothesis yang telah dimodifikasi dengan membedakan nilai gini coefficient, dengan garis vertikal dapat diganti dengan degradasi lingkungan hidup dan garis horizontal adalah pendapatan per kapita yang menjadi indikator kesejahteraan hasil representasi PDRB. Informasi nilai trade off dan degradasi lingkungan ditunjukkan pada Gambar 3.

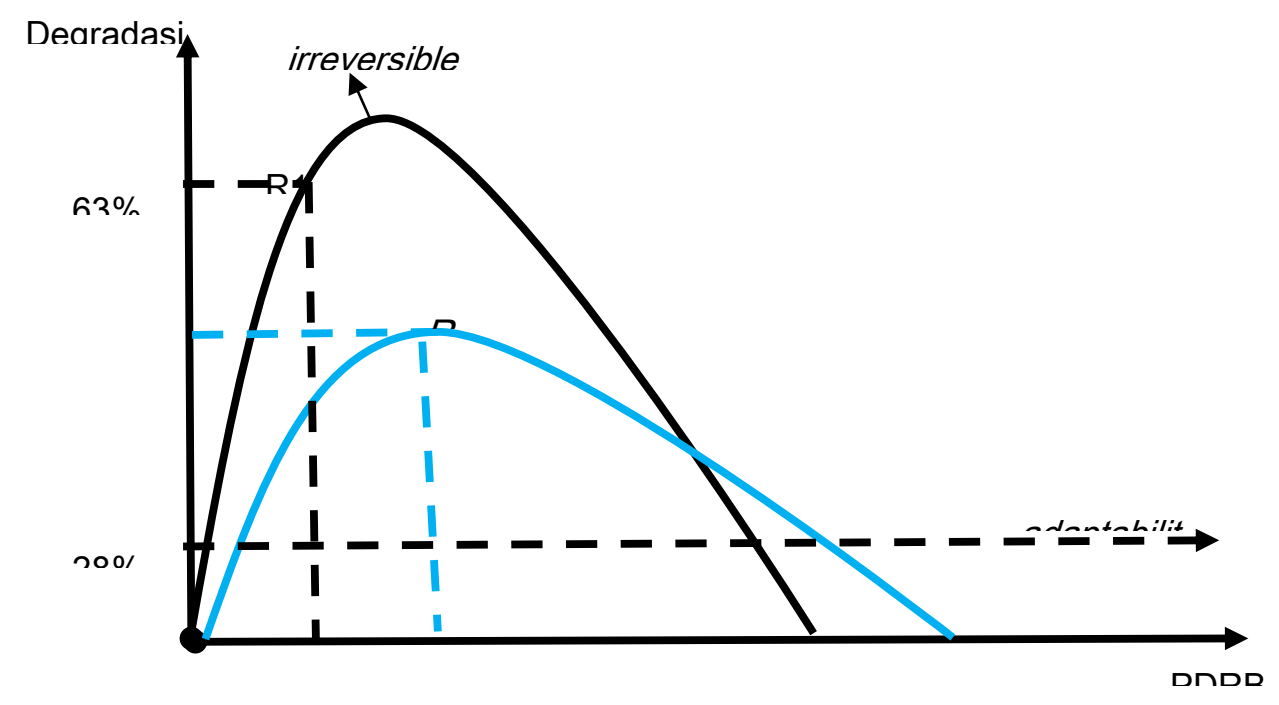

Gambar 3. Informasi nilai trade-off dan degradasi lingkungan (modifikasi Nurrochmat 2017 dan Kuznets 1955)

Gambar 3 menunjukkan pelaksanaan perencanaan pembangunan Kabupaten Jayapura dan perencanaan aksi mitigasi, dihubungkan dengan modifikasi Nurrocmat (2017) dan Kuznets (1955) di mana struktur ekonomi masih diikuti oleh kerusakan lingkungan yang rendah, yakni:

R1: Skenarion kenaikan pendapatan per kapita mengakibatkan peningkatan degradasi hutan, ketika tingkat 
kesejahteraan tercapai masyarakat akan peduli pada lingkungan. R1 adalah pengelolaan secara BAU dengan hasil proyeksi PDRB sebesar

R2: Skenario aksi mitigasi, jika dilakukan oleh Kabupaten Jayapura maka nilai PDRB akan berkurang dan mempengaruhi tingkat kesejahteraan masyarakat, maka untuk mencapai titik recovery menjadi lama.

Kabupaten Jayapura memiliki luas kawasan hutan sebesar 1.225.505 ha atau $70,73 \%$ dari luas Kabupaten Jayapura. Kawasan hutan terdiri dari Hutan Lindung 661.799 ha (38,04\%), Cagar Alam 8.262 ha (0,74\%), Hutan Suaka Marga Satwa 160.163 ha $(9,23 \%)$ dan Hutan Budidaya 395.281 ha $(22,72 \%)$. Mengacu pada Gambar 3, Perencanaan pembangunan untuk pertumbuhan ekonomi hijau, Kabupaten Jayapura dapat memanfaatkan sumberdaya hutan untuk pemerataan ekonomi. Sepanjang pemerintah menjadikan sumberdaya alam sebagai penghasil devisa dan dapat mencipatakan kesejahteraan masyarakat, maka kawasan yang dapat dijadikan sumberdaya stock carbon adalah kawasan konservasi dan kawasan hutan lindung (47,74\%). Kawasan konservasi $(9,70 \%)$ adalah kawasan yang tidak dapat diganggu keberadaannya secara pemanfaatan hasil hutan, namun dapat dijadikan sebagai pengembangan kawasan ekowisata, dengan memanfaatkan ekologi, kearifan lokal dan budaya masyarakat setempat untuk mendapatkan nilai ekonomi. Sementara, kawasan hutan lindung (38,04\%) adalah kawasan yang dapat dimanfaatkan untuk meningkatkan ekonomi masyarakat pemilik hak ulayat, dengan memanfaatkan hasil hutan bukan kayu. Budidaya agar berkontribusi dalam penurunan emisi di tingkat Provinsi Papua dan secara nasional, dengan tetap menjaga karbon tersimpan Kabupaten Jayapura.

Pemanfaatan kawasan hutan perlu memperhatikan faktor demografi, laju pertumbuhan ekonomi yang terintegrasi dalam rencana tata ruang. Batasan-batasan dalam fungsi kawasan menjadi indikator dalam RTRW, areal ijin seperti Hutan Tanaman Industri (HTI), Hak Guna Usaha (HGU), kesesuaian lahan, keberadaan Daerah Aliran Sungai (DAS) dan sistem tenurial. Selain mengacu pada pertumbuhan ekonomi, aksi mitigasi yang dilakukan juga mengacu pada pemeliharaan maupun peningkatan jasa lingkungan yang diperlukan masyarakat lokal, dengan mempertimbangkan kepentingan regional, nasional dan global. Setiap kawasan hutan lindung dan sempadan danau yang telah kehilangan vegetasi dapat diganti dengan tanaman agroforestri, sehingga masyarakat dapat meningkatkan pendapatannya (Arifin et al., 2009). Hal ini menjadi perhatian penting karena dipengaruhi oleh kepemilikan hak ulayat, sehingga masyarakat yang hak ulayatnya masuk dalam 
kawasan lindung mendapatkan manfaat ekonomi.

Pembangunan ekonomi hjau, dapat diartikan sebagai pembangunan yang melibatkan kapasitas masyarakat untuk terlibat dalam proses pembangunan. Pembangunan yang dibangun atas dasar kebutuhan mereka sendiri, dan perlibatan dalam pengambilan keputusan pemanfaatan sumberdaya alam atas dasar pengelolaan tanah dan sumberdaya alam. Kartasapoetra (1985) hak ulayat yang dimiliki oleh suatu persekutuan hukum adalah hak tertinggi atas tanah yang menjamin pemanfaatan atau pendayagunaan tanah.

Strategi pertumbuhan ekonomi hijau merupakan implementasi atau upaya terstruktur untuk mencapai tujuan yang diinginkan dalam prinsip-prinsip tujuan berkelanjutan (sustainable development goals/SDGs). Implementasi SDGs tersebut harus mempertimbangkan emisi sebagai dampak terhadap perubahan lingkungan dalam aktivitas sosial dan ekonomi. Strategi yang dapat dilakukan untuk mencapai pertumbuhan ekonomi hijau, adalah:

1. Dukungan kebijakan (policy making) percepatan pembangunan menuju ekonomi hijau.

Kebijakan pembangunan menuju ekonomi hijau adalah kebijakan yang membangun sektor primer yang memiliki produksi dan kualitas pengelolaan sumberdaya dan disesuaikan dengan nilai historis, geografis, kultur masyarakat dan penerapan teknologi tepat guna. Hal ini mengacu pada ketentuan umum dalam penerapan Permen Desa PDT'T Nomor 23 Tahun 2017 tentang Pengembangan dan Penerapan Teknologi Tepat Guna dalam Pengelolaan Sumberdaya Alam.

2. Perencanaan program dan kegiatan pembanguan daerah yang efisien, produktif, inovatif, sinergi dan terintegrasi pada berbagai sektor berbasis lahan, yaitu:

- Alokasi dan tataguna lahan berkelanjutan, yang harus sinergi antara kebutuhan dan ketersediaan lahan

- Peningkatan akses masyarakat terhadap modal penghidupan (livelibood capital) yang berbasis pada sektor lahan

- Peningkatan produktivitas dan diversifikasi teknologi dan praktek penggunaan lahan yang berkelanjutan

- Perbaikan rantai nilai dengan pembagian manfaat yang berkeadilan

- Peningkatan konektivitas dan skala ekonomi antar wilayah pengelolaan

- Restorasi lahan dan hutan yang terdegradasi

- Insentif jasa lingkungan dan pendanaan inovatif komoditas berkelanjutan

3. Kerjasama dan koordinasi (partnership) Upaya membangun kerjasama dengan pemangku kepentingan baik tingkat pusat, daerah, masyarakat dan swasta dalam pengelolaan kawasan hutan. 


\section{DAFTAR PUSTAKA}

[BAPPENAS] Badan Perencanaan Pembangunan Nasional. 2011. Rencana Aksi Nasional Pangan dan Gizi 2011 -2015. Jakarta (ID): BAPPENAS

[BPS Kab. Jayapura] Badan Pusat Statistik Kabupaten Jayapura. 2005. Kabupaten Jayapura dalam Angka 2013. Jayapura (ID): BPS Kabupaten Jayapura.

[CIFOR] Center for International Forestry Research. 2018. CIFOR Annual Report 1997. CIFOR (ID). Bogor.Indonesia

Arifin, H.S., Wulandari, C., Pramukanto, Q., Kaswanto, R.L. 2009. Analisis Lanskap Agroforestri: Konsep, Metode, dan Pengelolaan Agroforestri Skala Lanskap dengan Study Kasus Indonesia, Filipina, Laos, Thailand, dan Vietnam. IPB Press. Bogor, Indonesia.

Dewi, S., Suyanto, S., van Noordwijk, M. 2012. Melembagakan penurunan emisi sebagai bagian perencanaan pembangunan yang berkelanjutan pada tingkat nasional dan sub nasional di Indonesia. Brief No 31. Bogor, Indonesia. World Agroforestry Centre - ICRAF, SEA Regional Office. 6p.

Dewi, N.K. 2013. Identifikasi alih fungsi lahan pertanian dan kondisi sosial ekonomi masyarakat daerah pinggiran di Kecamatan Gunungpati Kota Semarang. J wilayah dan lingkungan. 1 (2):175-188.

[GGGI] Global Green Growth Institute. 2015. Mewujudkan Pertmbuhan Ekonomi Hijau untuk Indonesia yang Sejahtera. Jakarta (ID): The Jakarta Post.

Hariyadi. 2015. Kebijakan Mitigasi Perubahan Iklim Sektor Kehutanan Menyongsong RPJMN 2015-2019 di Provinsi Papua dan Provinsi Aceh. Politica. 6(2): 145-166.

[ICRAF] World Agroforestry Centre (ICRAF) Indonesia. 2017. Land Use Planning for Multiple Environmental Services (LUMENS). Bogor (ID):ICRAF \& ESP3. Indonesia.

Johana, F. 2014. Alternatif Perencanaan Penggunaan Lahan dalam Upaya Mitigasi Perubahan Iklim Berbasis Lahan di Kabupaten Merangin Provinsi Jambi. Tesis. Sekolah Pasca Sarjana Institut Pertanian Bogor: Bogor.

Kartasapoetra, G. 1985. Hukum Tanah Jaminan UUPA Bagi Keberhasilan Pendayagunaan Tanah, PT. Bina Aksara. Jakarta.

Kaswanto, R.L. and Nakagoshi, N. 2014. Landscape Ecology-Based Approach for Assessing Pekarangan Condition to Preserve Protected Area in West Java. Designing Low Carbon Societies in Landscapes, in Nakagoshi, N. and A. Mabuhay, J. (eds). Tokyo: Springer Japan, pp. 289-311.

Kementerian Sekertaris Negara. 1999. Undang-Undang No. 41 tahun 1999 tentang Kehutanan. Jakarta (ID). Kementerian Sekretariat Negara.

Kementerian Sekretaris Negara. 2016. Undang-Undang No. 16 tahun 2016 tentang Pengesahan Paris Agreement to The United Nations Framework Convention On Climate Change (persetujuan paris atas konvensi kerangka kerja perserikatan bangsa-bangsa mengenai perubahan iklim. Jakarta (ID). Kementerian Sekretariat Negara.

Kuznets, S. 1955. Economic Growth and Income Inequality. The American Economic Review. 45(1):1-28. 
Moolakkatu, S.J. 2010. "Peace Facilitation by Small States: Norway in Sri Lanka". Cooperation and Conflict: Nordic International Studies Assosiation, Vol 40.

[PP] Peraturan Presiden. 2011. Peraturan Presiden Nomor 61 Tahun 2011 tentang Rencana Aksi Nasional Penurunan Emisi Gas Rumah Kaca (RAN GRK). Jakarta (ID).

Pearce, D.W., Anil, M. Edward, B. 1992. Blueprint for Green Economy. London(UK): Earthscan Pub.

[UU] Undang-Undang. 2016. UndangUndang Nomor 16 Tahun 2016 tentang Pengesahan Paris Agreement To The United Nations Framework Convention On Climate Change (Persetujuan Paris Atas Konvensi Kerangka Kerja Perserikatan Bangsa-Bangsa Mengenai Perubahan Iklim). Jakarta (ID). 